\title{
Clinical significance of angiopoietin-like protein 3 expression in patients with glioblastoma
}

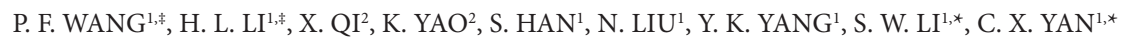 \\ ${ }^{1}$ Department of Neurosurgery, Sanbo Brain Hospital, Capital Medical University, China; ${ }^{2}$ Department of Pathology, Sanbo Brain Hospital, \\ Capital Medical University, China \\ *Correspondence: 15011339604@163.com,yancx65828@sina.com \\ ${ }^{*}$ Contributed equally to this work.
}

Received March 6, 2015 / Accepted July 29, 2015

\begin{abstract}
There is strong evidence that angiopoietin-like peptide family is involved in the invasiveness and metastasis of cancer. Angiopoietin-like protein 3 (ANGPTL3) is proven to be involved in angiogenesis and tumor development. However, there is no published data on the role ANGPLT3 plays in glioblastomas. The present study was conducted to examine ANGPLT3 proteins expression and its association with clinicopathological factors and prognosis in human glioblastomas. Immunohistochemistry was used to evaluate the expression of ANGPTL3, EGFR and VEGFR. We found that 33 cases (57.9\%) that showed strong immunostaining for ANGPTL3 proteins. However, there was no significant difference between the expression of ANGPTL3 and the proangiogenic factors, including EGFR or VEGFR. Patients with high/moderate expression of ANGPTL3 had a significantly shorter survival time (6.3 months) than those (median survival time 13.8 months) with low/ negative expression. The overall survival (OS) was also investigated and analyzed by the Kaplan-Meier method, which showed a significant difference $(\mathrm{P}=0.0045$, Breslow test). The present data leads to new insights into the role of ANGPTL3 in glioblastomas and provides an independent predictive factor.
\end{abstract}

Key words: ANGPTL3, glioblastoma, immunohistochemistry, prognosis, survival analysis

Glioblastoma is the most common primary malignant brain tumor in adults. The median survival of glioblastoma is 14.6 months and the 2 -year survival rate is only $26.5 \%$. The standard treatment for glioblastoma includes surgical resection followed by radiotherapy with concomitant and adjuvant temozolomide chemotherapy [1]. Although new drugs against glioblastoma entered clinical trials, no better improvements in outcome had been documented since 2005 [2, 3]. Nevertheless, there is a small fraction of patients who survive more than 3 years for reasons that are still unknown. Traditional pathohistology for glioblastoma are not enough to evaluate their survival and could not provide potential therapeutic value. Therefore, it is necessary to indentify novel molecular markers to better predict the course of the disease and to find the potential target.

Angiopoietin-protein like peptide 3 (ANGPTL3), a member of the angiopoietin-like family, is produced mainly in the liver [4]. Inactivation of ANGPTL3 results in a marked reduction of all plasma lipids and the absence of ANGPTL3 is associated with insulin sensitivity, suggesting it may play a role in modulating lipid and glucose metabolism $[5,6]$. Furthermore, ANGPTL3-deficient mice exhibits decreased population of hematopoietic stem cells(HSCs). Activation of ANGPTL3 could improve the expansion of the HSCs in vivo, suggesting that it could be a growth factor $[7,8]$. As a secreted protein, reduced levels of ANGPTL3 have also been detected in the patients with ovarian cancer [9]. Downregulation of ANGPTL3 in hepatocellular carcinoma cells inhibits cell proliferation and invasion in vitro [10]. However, there are no published data regarding the role of ANGPTL3 in gliomas to date. Interestingly, ANGPTL3 is also involved in the regulation of angiogenesis through stimulating endothelial cell adhesion and migration via integrin $\alpha_{v} \beta_{3}[11]$. The integrin $\alpha_{v} \beta_{3}$ is broadly expressed in glioblastomas and is associated with angiogenesis and malignancy of the tumor [12]. This prompts us to determine the expression of ANGPTL3 proteins by immunohistochemistry in glioblastomas. In the present study, we analyzed the characteristics of ANGPTL3 protein and related it to the clinicopathological parameters. Furthermore, we ac- 
cessed whether ANGPTL3 proteins levels could be used as an independent prognostic biomarker.

\section{Patients and methods}

Patients. From 2009 to 2012, 57 patients with newly diagnosed glioblastoma who underwent tumor resection at Beijing Sanbo Brain Hospital were enrolled for our study. Enrolled patients received radiotherapy (fractionated focal irradiation 2 Gy/day, 5 days/week for 6 weeks, 60 Gy totally) with concomitant and adjuvant temozolomide $\left(75 \mathrm{mg} / \mathrm{m}^{2}\right.$ day, 7 days/ week throughout radiotherapy followed by $150-200 \mathrm{mg} / \mathrm{m}^{2}$

Table 1. Relationship between angiopoietin-like protein 3 and clinicopathological factors

\begin{tabular}{|c|c|c|c|c|}
\hline \multirow[b]{2}{*}{ Characteristics } & \multirow{2}{*}{$\begin{array}{c}\text { total } \\
(\mathrm{n}=57)\end{array}$} & \multicolumn{2}{|c|}{ ANGPTL3 expression } & \multirow[b]{2}{*}{$\mathrm{P}$ value } \\
\hline & & $\begin{array}{l}\text { High/moderate } \\
(\mathrm{n}=33)\end{array}$ & $\begin{array}{c}\text { low/negative } \\
(\mathrm{n}=24)\end{array}$ & \\
\hline \multicolumn{5}{|l|}{ Gender } \\
\hline female & 25 & 14 & 11 & \multirow{2}{*}{0.798} \\
\hline male & 32 & 19 & 13 & \\
\hline \multicolumn{5}{|l|}{ Age } \\
\hline$\leq 55$ & 29 & 16 & 13 & \multirow{2}{*}{0.672} \\
\hline$>55$ & 28 & 17 & 11 & \\
\hline \multicolumn{5}{|l|}{ KPS } \\
\hline$>70$ & 29 & 16 & 13 & \multirow{2}{*}{0.672} \\
\hline$\leq 70$ & 28 & 17 & 11 & \\
\hline \multicolumn{5}{|l|}{ Location } \\
\hline Frontal & 15 & 9 & 6 & \multirow{5}{*}{0.053} \\
\hline Parietal & 6 & 4 & 2 & \\
\hline Temporal & 14 & 8 & 6 & \\
\hline Other site & 12 & 10 & 2 & \\
\hline Combined & 10 & 2 & 8 & \\
\hline \multicolumn{5}{|l|}{ Diameter $(\mathrm{cm})$} \\
\hline$\geq 4$ & 29 & 15 & 14 & \multirow{2}{*}{0.337} \\
\hline$<4$ & 28 & 18 & 10 & \\
\hline \multicolumn{5}{|l|}{ Resection } \\
\hline GTR & 49 & 28 & 21 & \multirow{2}{*}{0.776} \\
\hline non-GTR & 8 & 5 & 3 & \\
\hline \multicolumn{5}{|l|}{ p53 } \\
\hline positive & 40 & 23 & 17 & \multirow{2}{*}{0.926} \\
\hline negative & 17 & 10 & 7 & \\
\hline \multicolumn{5}{|l|}{ MGMT } \\
\hline positive & 32 & 21 & 11 & \multirow{2}{*}{0.181} \\
\hline negative & 25 & 12 & 13 & \\
\hline \multicolumn{5}{|l|}{ Ki-67 } \\
\hline positive & 19 & 12 & 7 & \multirow{2}{*}{0.569} \\
\hline negative & 38 & 21 & 17 & \\
\hline \multicolumn{5}{|l|}{ VEGFR } \\
\hline positive & 26 & 18 & 8 & \multirow{2}{*}{0.112} \\
\hline negative & 31 & 15 & 16 & \\
\hline \multicolumn{5}{|l|}{ EGFR } \\
\hline positive & 42 & 22 & 20 & \multirow{2}{*}{0.158} \\
\hline negative & 15 & 11 & 4 & \\
\hline
\end{tabular}

for 5 days during each cycle, 28 days per cycle for 6 cycles) postoperatively [1]. All investigations were approved by the Institutional Review Board of Beijing Sanbo Brain Hospital. Informed consent was obtained from all patients prior to the study. Overall survival (OS) was measured from diagnosis to death or censored. The deadline of the follow-up was 2014-924. At the last follow-up, only five were still alive and two of them had experienced tumor recurrence.

Immunohistochemical staining. Immunostaining was performed on 4- $\mu \mathrm{m}$-thick sections of formalin-fixed and paraffin-embedded samples. The sections were dewaxed by $x y-$ lene, dehydrated by gradient ethanol, and then rehydrated with PBS (Phosphate Buffered Saline). To facilitate antigen retrieval, the sections were incubated in $10 \mathrm{mM}$ of citric acid (pH 6.0) at $120^{\circ} \mathrm{C}$ for 150 seconds. We used $3 \%$ hydrogen peroxide to neutralize endogenous peroxidases of the samples for $15 \mathrm{~min}$. Primary antibodies against ANGPTL3 (1:150 dilutions, Abcam), p53 (1:100 Invitrogen), MGMT (1:150 Invitrogen), EGFR (1:150 Invitrogen), VEGFR (1:30 invitrogen) and Ki-67 (1:200 Invitrogen) were then applied overnight at $4^{\circ} \mathrm{C}$. After washing with PBS, the sections were then incubated with poly-HRP Anti-Mouse/Rabbit IgG Detection System (PV-9000 ZSGB-BIO, China) for $30 \mathrm{~min}$ at $37^{\circ} \mathrm{C}$. We used normal live tissue for both positive control and negative control according to the Human Protein Atlas.

Staining assessment. Two experienced observers (XL.Q and PF.W) reviewed the sections under microscope (Leica DM3000) independently, blind to clinical outcomes. The level of ANGPTL3 expression was evaluated according to the positive percentage and staining intensity of the immunoreactive cells [13]. The percentage of positive cells was rated as follows: 0 score for $0-10 \%$, 1 score for $10-25 \%, 2$ scores for $26-50 \%$, and 3 scores for more than $50 \%$. The staining intensity was rated as follows: 0 score for no staining, 1 score for weak staining, 2 scores for moderate staining, and 3 scores for strong staining. The scores from the percentage and intensity were added to an overall score, and the expression of the ANGPTL3 protein with an overall score of $0-2$ was designated as 'low/negative,' and with an overall score of 3-6 was designated as 'high/moderate.' The cutoff values were $10 \%$ for EGFR, 10\% for VEGFR, 5\% for p53, 10\% for MGMT, and $30 \%$ for Ki-67 respectively. (Fig. supplement)

Statistical analysis. All data analysis was carried out by SPSS 22.0. The association between the ANGPTL3 expression and clinicopathological characteristics were analyzed by $\chi^{2}$ test. Overall survival was analyzed by the Kaplan-Meier method, with use of both the Breslow test and the log-rank test. Survival data was evaluated using multivariate Cox regression analyses. $\mathrm{P}<0.05$ was taken as statistically significant.

\section{Results}

Clinicopathological data of the patients. Thirty-two male and Twenty-five female patients were enrolled in this study. The age at diagnosis ranged from 10 to 76 years (median age 52 years). (Table 1 ) The tumors were located in various 
regions and gross total resection was achieved in 49 patients. According to our categorization, more than one-third of the patients were positive for p53, MGMT, Ki-67, EGFR or VEGFR. (Table 1)

ANGPTL3 expression and the correlation between clinicopathological characteristics. For the immunostaining of ANGPTL3, we used liver tissue for the positive control and negative control. As was shown in Fig.1a, there was high expression of ANGPTL3 in the cytoplasm of hepatocytes as contrasted with the non-expression in biliary epithelial cell. Positive staining was detected in the cytoplasm of glioblastoma cells. Expression of ANGPTL3 was divided into high, moderate, low or negative expression. (Fig.1b,c,d,e) Moreo-

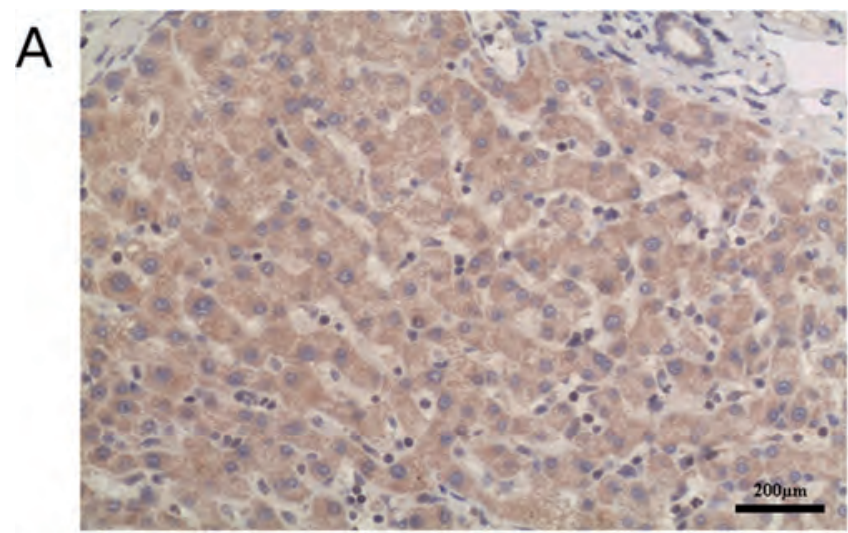

B
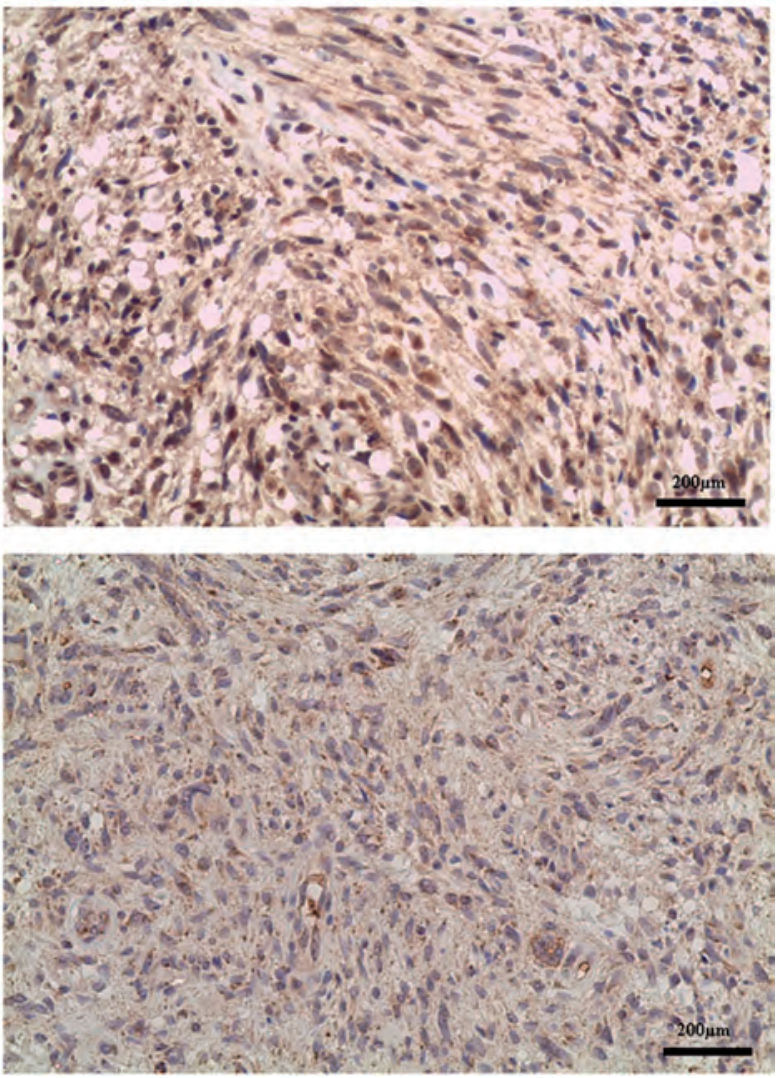

ver, the rate of ANGPTL3 protein high/moderate expression in glioblastoma and low/negative expression was $57.9 \%$ $(33 / 57)$ and $42.1 \%(24 / 57)$ respectively. (Table 1$)$ There was also no correlation between the expression of ANGPTL3 and patients' gender, age, preoperative KPS, tumor site, diameter or resection. Comparing ANGPTL3 expression and the status of molecular markers, no significance was also reached for MGMT, p53, Ki-67, EGFR or VEGFR. (Table 1)

Survival analysis. The median OS was 6.3 months or 13.8 months in patients with high/moderate expression or low/ negative expression of ANGPTL3 respectively. [median 6.300 months (95\% CI 3.419-9.181) vs. 13.830 months (95\% CI 8.513-19.147)] The significance was analyzed by the Kaplan-
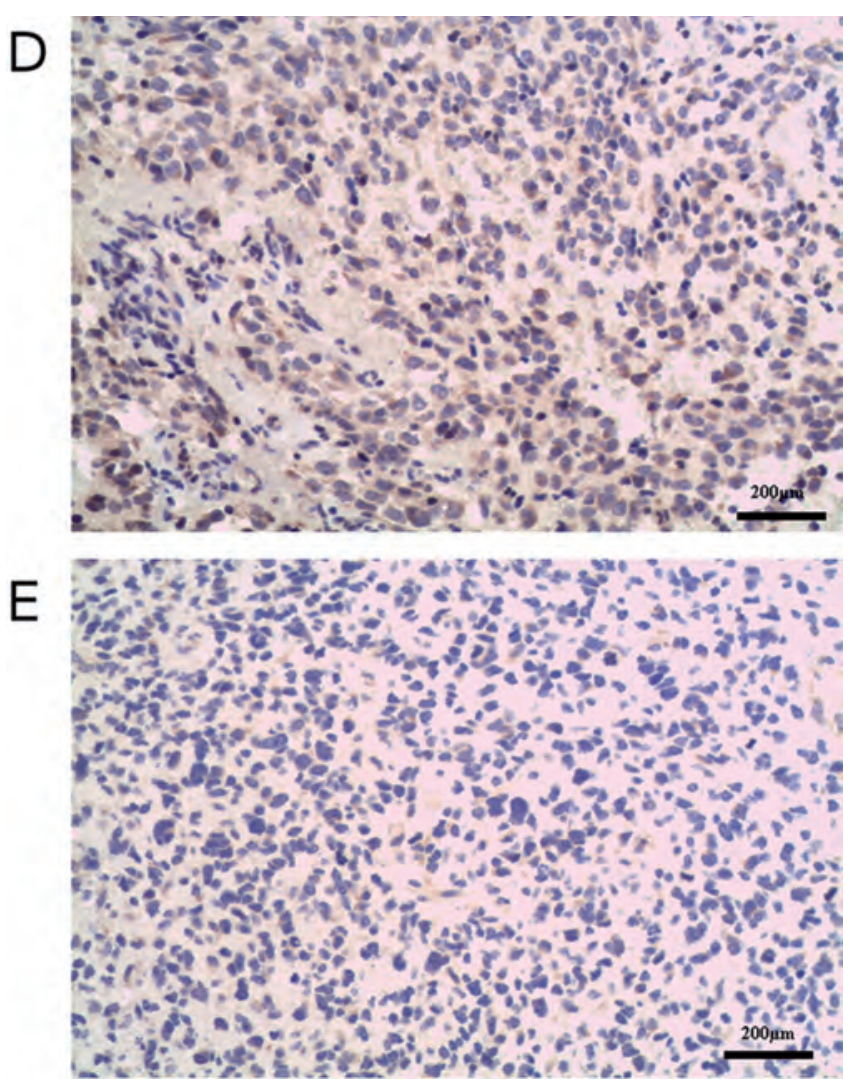

Figure 1. Immunohistochemical staining of ANGPTL3. Immunohistochemical detection and analysis of ANGPTL3 proteins in glioblastoma. Sections were subjected to an immunohistochemical staining using anti-ANGPTL3 polyclonal antibody (1:150 dilution). The evaluation of ANGPTL3 expression in tumor tissues was evaluated by percentage and intensity. A) ANGPTL3 was abundant in hepatocytes but was poor in bile cells. B) high expression of ANGPTL3 in glioblastoma. C) moderate expression of ANGPTL3 in glioblastoma. D) low expression of ANGPTL3 in glioblastoma. E) negative expression of ANGPTL3 in glioblastoma. The bar represents $200 \mu \mathrm{m}$. 


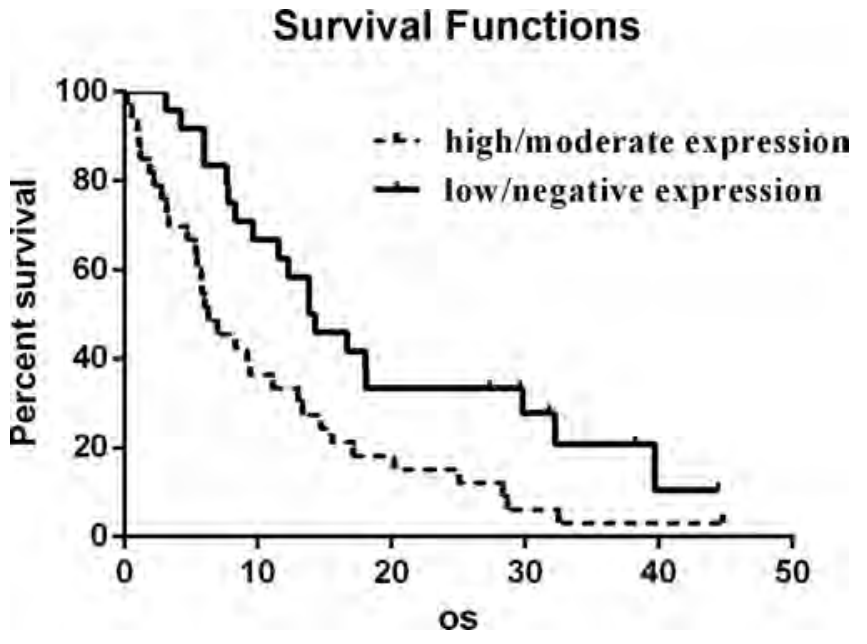

Figure 2. Kaplan-Meier survival curves and Breslow test for ANGPTL3 in GBM patients. Kaplan-Meier curves with Breslow test for patients with high/moderate and low/negative ANGPTL3 expression. The median overall survival was 6.300 months (95\% CI 3.419-9.181) in the group of high/moderate ANGPTL3 expression ( $n=33$ ), compared with 13.830 months (95\% CI 8.513-19.147) in the group of low/negative expression $(n=24)$. The statistical difference is significant as confirmed by the Breslow test $(\mathrm{p}=\mathbf{0 . 0 0 4 5})$.

Meier method, further confirmed by both the Breslow test $(\mathrm{P}=0.0045,<0.01)$ and the log-rank test $(\mathrm{P}=0.0088,<0.01)$. (Fig.2) Furthermore, multiple Cox regression, including the above-mentioned parameters, showed ANGPTL3 expression was an independent factor for predicting OS for patients with glioblastoma (Table 2).

\section{Discussion}

Angiopoietin-like proteins (ANGPTLs) are a family that is structurally similar to the angiopoietins, consisting of a $\mathrm{N}$ -

Table2. Multivariate analysis of clinicopathological factors for overall survival (OS) of patients with glioblastoma

\begin{tabular}{lcccc}
\hline $\begin{array}{l}\text { independent } \\
\text { variables }\end{array}$ & OR & \multicolumn{2}{c}{$95 \%$} & P value \\
\hline sex & & Lower & Upper & \\
age & 0.943 & 0.479 & 1.858 & 0.866 \\
KPS & 1.385 & 0.725 & 2.648 & 0.324 \\
location & 1.344 & 0.684 & 2.641 & 0.392 \\
diameter & 1.101 & 0.840 & 1.444 & 0.486 \\
resection & 0.598 & 0.307 & 1.162 & 0.129 \\
EGFR & 1.953 & 0.759 & 5.024 & 0.165 \\
P53 & 0.711 & 0.338 & 1.497 & 0.369 \\
Ki-67 & 0.937 & 0.420 & 2.089 & 0.873 \\
MGMT & 1.700 & 0.806 & 3.588 & 0.164 \\
VEGFR & 0.870 & 0.415 & 1.820 & 0.711 \\
ANGPTL3 & 1.061 & 0.555 & 2.029 & 0.858 \\
\hline
\end{tabular}

terminal coiled-coil domain and a C-terminal fibrinogen-like domain $[14,15]$. However, ANGPTLs function to regulate angiogenesis and do not bind to the angiopoietin receptors Tie1 or Tie2 [15]. ANGPTL8 is the exception of the family because of the absence of a C-terminal fibrinogen-like domain. To date, ANGPTLs has established a role in lipid and glucose metabolism, angiogenesis and cancer [14]. However, reports about the role of ANGPTLs in cancer were nearly blank, except for ANGPTL1 and ANGPTL4. ANGPTL3 is strongly involved in the development of cancer, for example ovarian cancer and liver cancer $[9,10]$. Here, we are the first to characterize the role of ANGPTL3 expression in glioblastomas. We also confirmed that ANGPTL3 could be used as an independent marker in glioblastomas. Inhibition of ANGPTL3 may provide a novel and potential therapeutic target against glioblastomas in the future. However, much work is still needed to confirm the role of ANGPTL3 in gliomas and to underline the mechanism behind it.

The glioblastoma cells often exploits the existing host vessels to grow or invade, which is vessel cooption $[16,17]$. Vessel cooption was a strong explanation for the invasion or metastasis of malignant brain tumors [16-20]. The coopted vasculature initiates structural and functional change to better suit glioma growth [21]. The invasive glioma cells, often far from the tumor mass, remodel the vasculature by inducing vascular loop, glomeruloid-like body and dilate the microvessel, further promoting angiogenesis [19]. However, ANGPTL3 was proved to increase the permeability of glomerular endothelial cell (GenCs) via integrin $\alpha_{v} \beta_{3}$, promoting the development of proteinuria $[22,23]$. ANGPTL3 could also promote angiogenesis by stimulating endothelial cell adhesion and migration via integrin $\alpha_{v} \beta_{3}$ [11]. The presence of integrin $\alpha_{v} \beta_{3}$ could be detected not only in the blood vessels but also in the glioblastoma cells [12]. This evidence suggests that ANGPTL3 may also dilate the coopted vessels in the brain and increase the permeability of the vasculature via integrin $\alpha_{v} \beta_{3}$, consequently promoting the invasion of glioblastoma.

Blockade of integrin $\alpha_{\mathrm{v}} \beta_{3}$ inhibited the progression of the tumor in glioblastoma model and suggested better prognosis in trials $[24,25]$. However, for Cilengitide, the selective inhibitor of integrin $\alpha_{v} \beta_{3}$, combined with standard treatment showed no benefit in patients with primary glioblastoma [3]. The trial was restricted to the patients with methylated MGMT promoter, though there were no documents about the relationship between the status of MGMT and cilengitide activity [26]. However, we still need to assess the potential therapeutic value of cilengitide in patients with high expression of ANGPTL3, which is mediated by integrin $\alpha_{\mathrm{v}} \beta_{3}$. Bevacizumab, an antiVEGF-A molecular drug, showed benefit in progression-free survival but not in overall survival [2]. Since 2005, many antiangiogenic agents, targeting various molecules, have entered clinic trial but no better results have been documented [2] ANGPTLs family participates in the regulation of angiogenesis but there are few reports concerning the relationship between the ANGPTLs and glioma. ANGPTL1 was proven to increase 
capillary destabilization and promote glioma growth and invasiveness by vessel cooption [16]. ANGPTL4 was increased by epidermal growth factor variant type III (EGFRvIII) and involved in the angiogenesis and glioma growth [27]. Our study first described the correlation between ANGPTL3 and glioblastoma. We hope that our study could attract more attention on the relationship between gliomas and ANGPTLs family. The family may provide a reason for the mechanism of malignance of glioblastoma. We believe that ANGPTLs family may become a therapeutic target for glioblastoma in the future.

In conclusion, this study first detected the expression of ANGPTL3 proteins in glioblastoma and proved it to be an independent marker of prognosis in patients' overall survival. We also suggested that integrin $\alpha_{\mathrm{v}} \beta_{3}$ may mediate ANGPTL3 for promoting vessel cooption and angiogenesis and promote the invasiveness and growth of glioblastoma. But much more work is needed to confirm the hypothesis. We hope our study could attract more attention in ANGPTLs family as they may make a potential target for treating glioblastoma in the future.

Supplementary information is available in the online version of the paper.

Acknowledgments: This work was supported by Capital Applied Research with Clinical characteristics from Beijing (No. Z121107001012064), China and National Youth Science Fund from China (No.81302200), China.

\section{References}

[1] STUPP R, MASON WP, VAN DEN BENT MJ, WELLER M, FISHER B et al. Radiotherapy plus concomitant and adjuvant temozolomide for glioblastoma. The New England journal of medicine 2005; 352: 987-996. http://dx.doi.org/10.1056/ NEJMoa043330

[2] CHINOT OL, WICK W, MASON W, HENRIKSSON R, SARAN F et al. Bevacizumab plus radiotherapy-temozolomide for newly diagnosed glioblastoma. The New England journal of medicine 2014; 370: 709-722. http://dx.doi. org/10.1056/NEJMoa1308345

[3] STUPP R, HEGI ME, GORLIA T, ERRIDGE SC, PERRY J et al. Cilengitide combined with standard treatment for patients with newly diagnosed glioblastoma with methylated mgmt promoter (centric eortc 26071-22072 study): A multicentre, randomised, open-label, phase 3 trial. The Lancet Oncology 2014; 15: 1100-1108. http://dx.doi.org/10.1016/S1470-2045(14)70379-1

[4] CONKLIN D, GILBERTSON D, TAFT DW, MAURER MF, WHITMORE TE et al. Identification of a mammalian angiopoietin-related protein expressed specifically in liver. Genomics 1999; 62: 477-482. http://dx.doi.org/10.1006/ geno.1999.6041

[5] MiNiCOCCI I, MONTALI A, ROBCIUC MR, QUAGLIARINI F, CENSI V ET AL. Mutations in the angptl3 gene and familial combined hypolipidemia: A clini- cal and biochemical characterization. The Journal of clinical endocrinology and metabolism 2012; 97: E1266-1275. http:// dx.doi.org/10.1210/jc.2012-1298

[6] ROBCIUC MR, MARANGHI M, LAHIKAINEN A, RADER D, BENSADOUN A et al. Angptl3 deficiency is associated with increased insulin sensitivity, lipoprotein lipase activity, and decreased serum free fatty acids. Arteriosclerosis, thrombosis, and vascular biology 2013; 33: 1706-1713. http://dx.doi. org/10.1161/ATVBAHA.113.301397

[7] ZHANG CC, KABA M, GE G, XIE K, TONG W et al. Angiopoietin-like proteins stimulate ex vivo expansion of hematopoietic stem cells. Nature medicine 2006; 12: 240-245. http://dx.doi.org/10.1038/nm1342

[8] ZHENG J, HUYNH H, UMIKAWA M, SILVANY R, ZHANG CC. Angiopoietin-like protein 3 supports the activity of hematopoietic stem cells in the bone marrow niche. Blood 2011; 117: 470-479. http://dx.doi.org/10.1182/blood-201006-291716

[9] LIN B, WHITE JT, WU J, LELE S, OLD LJ et al. Deep depletion of abundant serum proteins reveals low-abundant proteins as potential biomarkers for human ovarian cancer. Proteomics Clinical applications 2009; 3: 853-861. http:// dx.doi.org/10.1002/prca.200800141

[10] YU H, ZHANG H, LI D, XUE H, PAN C et al. Effects of angptl3 antisense oligodeoxynucleotides transfection on the cell growths and invasion of human hepatocellular carcinoma cells. Hepato-gastroenterology 2011; 58: 1742-1746. http:// dx.doi.org/10.5754/hge10647

[11] CAMENISCH G, PISABARRO MT, SHERMAN D, KOWALSKI J, NAGEL M et al. Angptl3 stimulates endothelial cell adhesion and migration via integrin alpha vbeta 3 and induces blood vessel formation in vivo. The Journal of biological chemistry 2002; 277: 17281-17290. http://dx.doi.org/10.1074/jbc. M109768200

[12] ROTH P, SILGINER M, GOODMAN SL, HASENBACH K, THIES S et al. Integrin control of the transforming growth factorbeta pathway in glioblastoma. Brain : a journal of neurology 2013; 136: 564-576. http://dx.doi.org/10.1093/brain/aws351

[13] YI J, PAN BZ, XIONG L, SONG HZ. Clinical significance of angiopoietin-like protein 4 expression in tissue and serum of esophageal squamous cell carcinoma patients. Medical oncology 2013; 30: 680. http://dx.doi.org/10.1007/s12032013-0680-y

[14] SANTULLI G. Angiopoietin-like proteins: A comprehensive look. Frontiers in endocrinology 2014; 5: 4. http://dx.doi. org/10.3389/fendo.2014.00004

[15] HATO T, TABATA M, OIKE Y. The role of angiopoietin-like proteins in angiogenesis and metabolism. Trends in cardiovascular medicine 2008; 18: 6-14. http://dx.doi.org/10.1016/j. $\underline{\mathrm{tcm} .2007 .10 .003}$

[16] BEAUDET MJ, RUEDA N, KOBINGER GP, VILLENEUVE J, VALLIERES L. Construction of a ganciclovir-sensitive lentiviral vector to assess the influence of angiopoietin-3 and soluble tie2 on glioma growth. Journal of neuro-oncology 2010; 99: 1-11. http://dx.doi.org/10.1007/s11060-009-0095-y

[17] HOLASH J, MAISONPIERRE PC, COMPTON D, BOLAND P, ALEXANDER CR et al. Vessel cooption, regression, and growth 
in tumors mediated by angiopoietins and vegf. Science 1999; 284 : 1994-1998. http://dx.doi.org/10.1126/science.284.5422.1994

[18] CARBONELL WS, ANSORGE O, SIBSON N, MUSCHEL R. The vascular basement membrane as „,soil“ in brain metastasis. PloS one 2009; 4: e5857. http://dx.doi.org/10.1371/journal. pone. 0005857

[19] WINKLER F, KIENAST Y, FUHRMANN M, VON BAUMGARTEN L, BURGOLD S et al. Imaging glioma cell invasion in vivo reveals mechanisms of dissemination and peritumoral angiogenesis. Glia 2009; 57: 1306-1315. http://dx.doi. org/10.1002/glia.20850

[20] AUF G, JABOUILLE A, GUERIT S, PINEAU R, DELUGIN $\mathrm{M}$ et al. Inositol-requiring enzyme 1alpha is a key regulator of angiogenesis and invasion in malignant glioma. Proceedings of the National Academy of Sciences of the United States of America 2010; 107: 15553-15558. http://dx.doi.org/10.1073/ pnas.0914072107

[21] FISCHER I, GAGNER JP, LAW M, NEWCOMB EW, ZAGZAG D. Angiogenesis in gliomas: Biology and molecular pathophysiology. Brain pathology 2005; 15: 297-310. http:// dx.doi.org/10.1111/j.1750-3639.2005.tb00115.x

[22] LI Y, SUN L, XU H, FANG Z, YAO W et al. Angiopoietin-like protein 3 modulates barrier properties of human glomerular endothelial cells through a possible signaling pathway involving phosphatidylinositol-3 kinase/protein kinase $\mathrm{b}$ and integrin alphavbeta3. Acta biochimica et biophysica Sinica 2008; 40: 459-465. http://dx.doi.org/10.1111/j.1745-7270 .2008.00421.X

[23] LIN Y, RAO J, ZHA XL, XU H. Angiopoietin-like 3 induces podocyte $\mathrm{f}$-actin rearrangement through integrin alpha(v) beta(3)/fak/pi3k pathway-mediated racl activation. BioMed research international 2013; 2013: 135608.

[24] MACDONALD TJ, TAGA T, SHIMADA H, TABRIZI P, ZLOKOVIC BV et al. Preferential susceptibility of brain tumors to the antiangiogenic effects of an alpha(v) integrin antagonist. Neurosurgery 2001; 48: 151-157.

[25] MIKKELSEN T, BRODIE C, FINNISS S, BERENS ME, RENNERT JL et al. Radiation sensitization of glioblastoma by cilengitide has unanticipated schedule-dependency. International journal of cancer Journal international du cancer 2009; 124: 2719-2727. http://dx.doi.org/10.1002/ijc.24240

[26] CHINOT OL. Cilengitide in glioblastoma: When did it fail? The Lancet Oncology 2014; 15: 1044-1045. http://dx.doi. org/10.1016/S1470-2045(14)70403-6

[27] KATANASAKA Y, KODERA Y, KITAMURA Y, MORIMOTO T, TAMURA T et al. Epidermal growth factor receptor variant type iii markedly accelerates angiogenesis and tumor growth via inducing c-myc mediated angiopoietin-like 4 expression in malignant glioma. Molecular cancer 2013; 12: 31. http:// dx.doi.org/10.1186/1476-4598-12-31 
doi:10.4149/neo_2016_011

\title{
Supplementary Information
}

\section{Clinical significance of angiopoietin-like protein 3 expression in patients with glioblastoma}

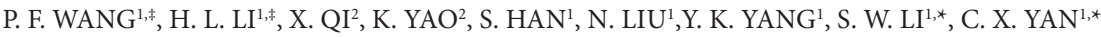

${ }^{1}$ Department of Neurosurgery, Sanbo Brain Hospital, Capital Medical University, China; ${ }^{2}$ Department of Pathology, Sanbo Brain Hospital, Capital Medical University, China

*Correspondence: 15011339604@163.com,yancx65828@sina.com

${ }^{*}$ Contributed equally to this work.
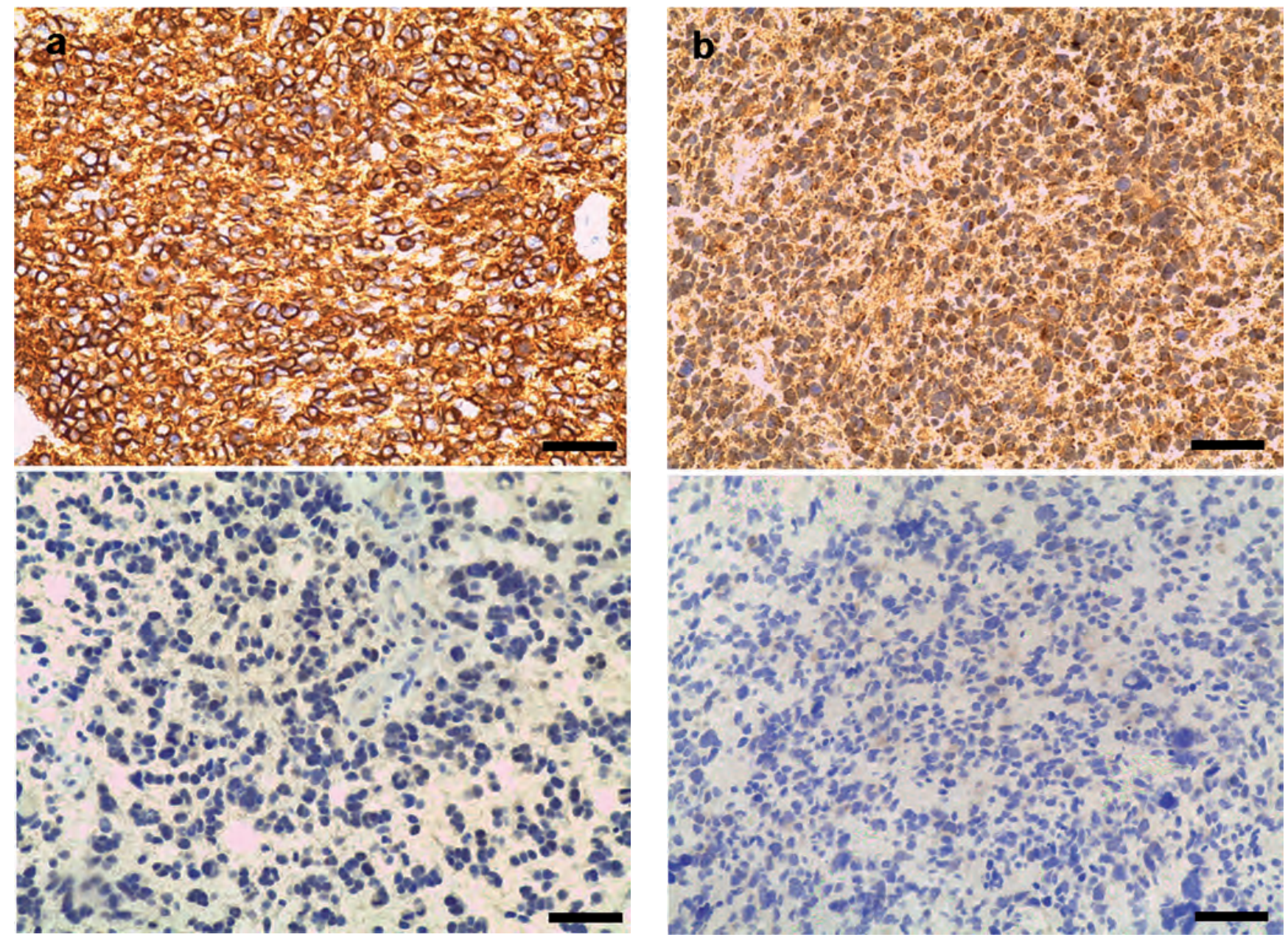

Supplementary Figure 1: Positive and negative staining for EGFR(a), VEGFR(b), p53(c), MGMT(d) and Ki-67(e) respectively. 

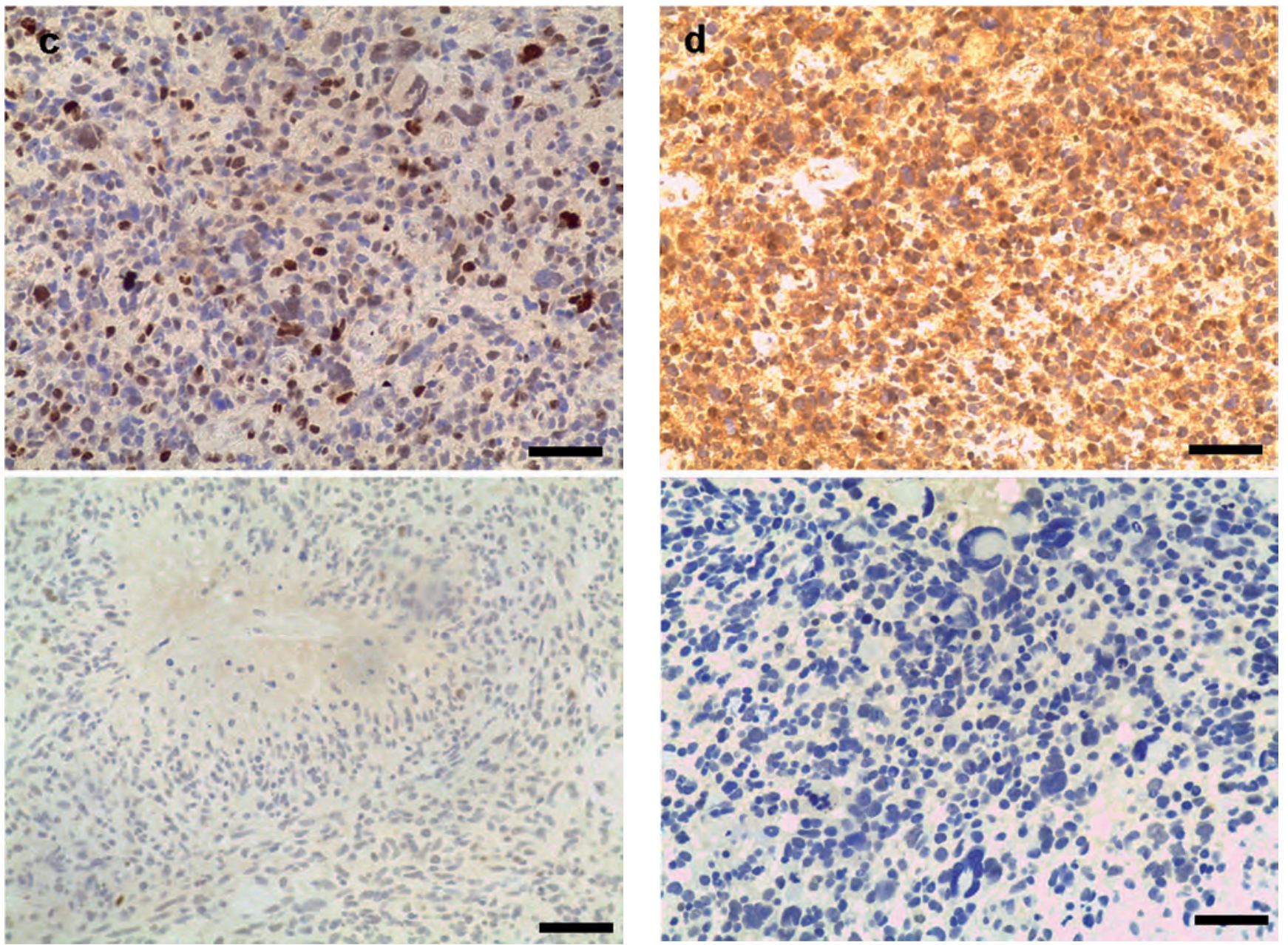

Supplementary Figure 2: Positive and negative staining for EGFR(a), VEGFR(b), p53(c), MGMT(d) and Ki-67(e) respectively. 


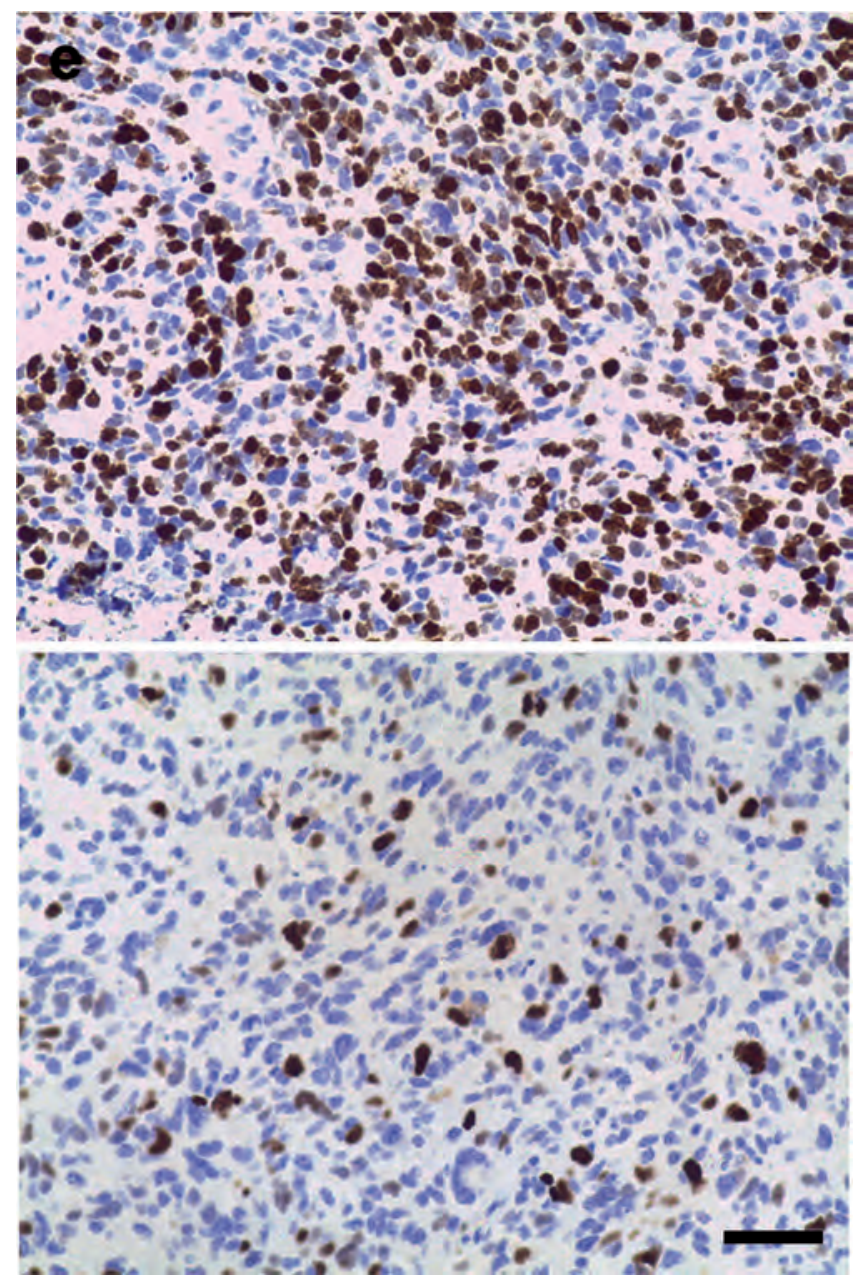

Supplementary Figure 3: Positive and negative staining for $\operatorname{EGFR(a),~}$ $\operatorname{VEGFR(b),~p53(c),~MGMT(d)~and~Ki-67(e)~respectively.~}$ 